\title{
Relevamientos de espacios exteriores en la ciudad de Maldonado
}

\author{
External Space Surveys in Maldonado City
}

\author{
Alejandro Folga ${ }^{1}$
}

\begin{abstract}
En este artículo se presenta una experiencia pedagógica desarrollada durante varios años en la asignatura Representación Gráfica del Espacio, perteneciente a la Licenciatura de Diseño de Paisaje. El trabajo consistió en el relevamiento y el registro gráfico de espacios exteriores que forman parte de edificios públicos vinculados a la cultura, en la ciudad de Maldonado. Se trata de edificios organizados en torno a patios y galerías. Un aspecto destacado de estos espacios es que en ellos la arquitectura actúa como el marco del paisaje y el vegetal complementa a lo edilicio, lo que resulta adecuado para la enseñanza del diseño de paisaje. En el artículo se desarrolla la metodología didáctica aplicada, se explican las técnicas gráficas enseñadas y finalmente se presentan algunos de los gráficos generados por los estudiantes como resultado del curso.
\end{abstract}

Palabras clave: Paisajismo; Enseñanza; Representación gráfica; Patrimonio

This paper presents a pedagogical experience developed during several years in the course Graphic Representation of the Space that belongs to the Degree in Landscape Design. The work consisted in the registration and the graphic representation of exterior spaces belonging to public buildings, linked to the culture of the city of Maldonado. These buildings are organized around patios and galleries. The valuable thing about studying these spaces is that in them architecture acts as the framework of the landscape and the landscape complements the building, which is appropriate for the teaching of landscape design. In the article the didactic methodology is developed, 
the graphic techniques taught are explained and finally some of the graphics generated by the students as a result of the course are presented.

Keywords: Landscape; Education; Graphic representation; Heritage

\section{INTRODUCCIÓN}

Inscripto al eje temático "Puesta en valor de recursos naturales y culturales: Paisaje y patrimonio" (uno de los ejes propuestos para el Coloquio-Debate Viento del Este) este artículo desarrolla una experiencia pedagógica llevada a cabo desde el año $2012^{2}$ por el equipo docente ${ }^{3}$ del curso curricular Representación Gráfica del Espacio II (RGE2). Este curso pertenece a la Licenciatura de Diseño de Paisaje (LDP) de la Universidad de la República (UdelaR) y se dicta en el Centro Universitario Regional Este (CURE) radicado en la ciudad de Maldonado (Uruguay).

La experiencia consistió en el revelamiento métrico y en la representación gráfica de espacios exteriores ubicados en edificios de uso público en la ciudad de Maldonado. Los edificios en los que hemos trabajado durante estos años son: la Casa de la Cultura de Maldonado (relevada en los años 2012 y 2013), el Cuartel de Dragones (relevado en los años 2014 y 2015) y el Paseo de San Fernando (en el que actualmente estamos trabajando con los estudiantes de la generación 2017). En definitiva, se trata de tres espacios que, además de interés arquitectónico y paisajístico, poseen valor histórico y cultural para la población local.

En primer lugar, en este artículo se desarrollará el marco teórico del trabajo. En esa sección nos focalizaremos en las relaciones entre la representación y el proyecto. En segundo término, se explican los criterios para la elección de las obras estudiadas y se hace una breve reseña de los valores históricos, arquitectónicos y culturales de cada caso. En la tercera parte se presenta la metodología didáctica aplicada en el ejercicio, en donde se desarrollarán: las estrategias de enseñanza, las técnicas de relevamiento ${ }^{4}$ y los diferentes ejercicios gráficos realizados. En especial nos centraremos en las diferentes herramientas y técnicas gráficas ensayadas (analógicas y digitales), en la interacción de los recursos tradicionales con las herramientas informáticas (técnicas o sistemas mixtos) y en la enseñanza de los códigos y criterios gráficos para representar espacios exteriores. Esta sección se ilustra con abundantes trabajos gráficos generados por los estudiantes del curso RGE2. En tercer lugar, se reflexiona y evalúan los resultados del curso.

2 La experiencia que se relata abarca un periodo continuo que va desde 2012 a 2015. En el año 2016 realizamos el relevamiento de un espacio exterior que no tenía las mismas características que presentan los casos presentados en este artículo. Dado que en esa oportunidad los resultados obtenidos no fueron satisfactorios para el equipo docente, en 2017 retomamos la anterior línea de trabajo.

3 El equipo docente de RGE2 está formado por cuatro profesores. En el período 2012 - 2014 el equipo estuvo integrado por los profesores adjuntos Alejandro Folga y Elena Porteiro, y por los ayudantes Claudia Espinosa y Federico Trener. En el período 2014 2016 estuvo integrado por los profesores adjuntos Alejandro Folga y Andrés Nogués y los ayudantes Claudia Espinosa y Federico Trener. Actualmente se integra por: Alejandro Folga, Claudia Espinosa, Federico Trener y Luis Flores.

4 Los métodos de relevamiento que se presentan en este artículo se relacionan con otros trabajos que he publicado anteriormente. En particular, en la ponencia "La trazabilidad del patrimonio arquitectónico del estado" (Folga y Gómez, 2016) hemos desarrollado la metodología de relevamiento gráfico de obras patrimoniales. Por otro lado, en la ponencia "Imágenes Alteradas: un ejercicio de interpretación gráfica sobre el sitio de proyecto" (Folga, 2017) se explica una actividad realizada en el taller de anteproyectos que tiene como objetivo plasmar, mediante un trabajo gráfico, las ideas y percepciones que genera la primera visita al sitio en que se va a proyectar. Por último, algunos temas que se tratan en el marco teórico fueron desarrollados en la investigación "La representación del espacio en el Proyecto de Paisaje", proyecto financiado mediante el "Llamado interno de proyectos de investigación FADU", edición 2015 (investigador responsable: Alejandro Folga, colaboradora: Claudia Espinosa). 


\section{MARCO TEÓRICO}

Dado que, ante todo, soy un docente-arquitecto voy a ceder a la tentación de empezar esta sección con una frase de Le Corbusier, pues tiene una relación directa con la temática que nos ocupa:

La clave es mirar. Mirar, observar, ver, imaginar, inventar, crear (Le Corbusier, citado en de Lapuerta, 1997, p. 54.)

Mientras que el mirar frecuentemente se relaciona con el vistazo rápido, el observar está asociado a un mayor detenimiento. El diccionario de la Real Academia Española (RAE) nos informa que observar es un verbo que implica "mirar con atención y recato". El mismo diccionario nos suministra un total de 22 definiciones diferentes sobre lo que es ver, que abarcan desde lo meramente fisiológico hasta lo cuasi sobrenatural. Sin dudas, en el uso que Le Corbusier hace del término ver, subyace un sentido de entendimiento conceptual, que define un acto de razonamiento o iluminación intelectual. Por eso el crescendo que lleva desde un inocente mirar pasa por la observación atenta y dispara procesos mentales que nos permiten llegar al ver.

Pero la verdadera "clave" está en la segunda parte de la frase: "imaginar, inventar, crear". Este nuevo crescendo, más intenso todavía, nos sugiere que el acto superior (pues linda con lo "divino") de crear está precedido por el más modesto inventar, que a su vez deriva de la capacidad de imaginar. Podemos concluir que la lección del Maestro consiste en enseñarnos que en la simple mirada subyace el inicio de la creatividad, pues aprendemos mirando. 0 , mejor aún: sabiendo mirar seremos capaces de crear.

Para Le Corbusier el dibujo es la verdadera “clave" para ver. Le Corbusier se manifestó en múltiples oportunidades sobre las ventajas del dibujo en comparación con la fotografía, relegando siempre a la segunda a mero instrumento técnico. Sirva como ejemplo esta cita en la que el Maestro se refiere a sus dibujos de viaje:

...uno usa los ojos para fijar profundamente en la propia experiencia lo que se ve. Una vez que la impresión ha sido grabada por el lápiz, queda para siempre: anotada, registrada, inscrita. La cámara es una herramienta para ociosos que usan una máquina para que vea por ellos. (Le Corbusier, 1960 citado en Colomina, 2010;82).

Lo que Le Corbusier nos dice es que gracias al dibujo podemos reflexionar y alcanzar un entendimiento de lo visto, mientras que la inmediatez del registro fotográfico no lo permite. El dibujar un espacio existente nos exige una mirada profunda de lo que se está representando. Una mirada analítica y atenta a los detalles. En definitiva: una mirada que es muy distinta al registro fotográfico de lo observado.

Por otro lado y enganchando directamente con el diseño de paisaje, Waterman y Wall (2013) afirman que durante el proceso de diseño la representación del paisaje cumple dos funciones fundamentales: "Primero, a través de la observación y el apunte [...] Luego, a través del proyecto y la transformación" (p.38). Los autores reconocen dos tiempos que se suceden en la acción del proyectista: el registro de un estado previo y la propuesta de modificación. Más adelante aclaran que la toma de datos y el análisis del sitio deben entenderse como "una fase 
puramente objetiva en la que se obtiene una imagen estática con el objetivo de comprender el lugar y su contexto" (p.38). Esa "imagen estática" es el registro que pretendemos conseguir mediante nuestro ejercicio de relevamiento de espacios exteriores.

Casi desde los orígenes del paisajismo los proyectistas se han dedicado a mostrar sus propuestas en función de las preexistencias, pues para diseñar un paisaje es indispensable conocer y entender el antes que justificará (y a veces determinará) el después. Las imágenes de "antes y después" han sido fundamentales en la historia de esta profesión para indicar cómo cambia el espacio con una intervención. Sin dudas, el caso más conocido y estudiado es el de Humphrey Repton, arquitecto y paisajista inglés que a fines del siglo XVIII inventó y puso a punto un método de representación que consistía en mostrar una vista del lugar intervenido, contraponiéndola con la situación existente (ver fig. 01).

En su libro, El dibujo en el proyecto del paisaje, Edward Hutchison (2012) nos advierte que: "En arquitectura, el proyecto de un edificio puede ser novedoso, pero el de un paisaje consiste siempre en convertir un lugar preexistente en algo distinto" (p.46). Por ello el autor recomienda desarrollar una propuesta que acepte lo existente como punto de partida para su transformación, para lo cual debemos "entender el contexto" a través de su representación gráfica.
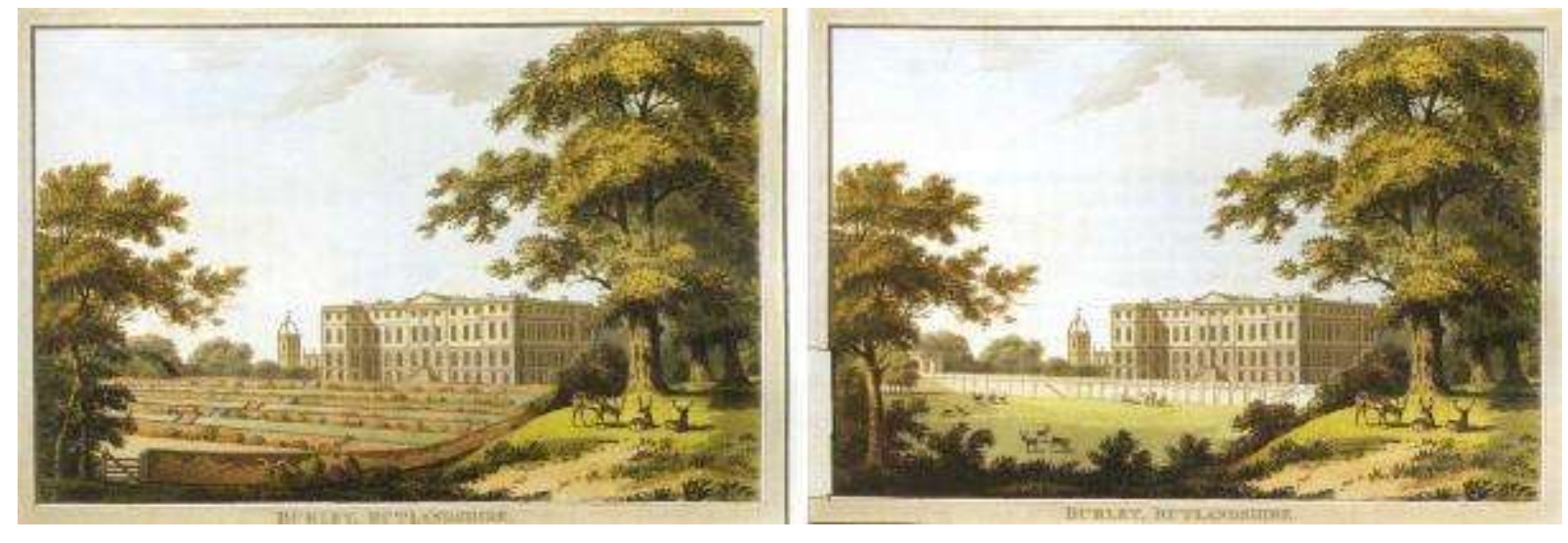

Figura 1. Dibujos del libro Observations on the Theory and Practice of Landscape Gardening, Humphrey Repton (1803).

Fuente: http:// bit.ly/2idlWay.

En el mismo sentido, en el artículo “Las cinco puertas del paisaje”, Besse (2006) nos dice: “Qué es proyectar cuando el espacio no es una página en blanco o una tabla rasa?". Luego de la pregunta retórica, el autor propone el análisis de la doble acepción que posee el término proyectar:

Proyectar el paisaje sería a la vez [...] representarlo (proyección) e imaginar lo que podría llegar a ser (proyectación). Esta ambigüedad, o esta circularidad, es constitutiva de la idea misma de proyecto en el pensamiento del paisaje. Pone en relieve las dos dimensiones contenidas en el acto de proyectar: atestiguar, por una parte, y modificar, por otra. (p.168)

La representación de lo existente cumple así dos objetivos, que se pueden explicar con un 
juego de palabras: relevar y revelar. Relevar un espacio (hacer un relevamiento) es una primera instancia para revelar (en el sentido de descubrir algo que está oculto) lo que ese espacio podría llegar a ser.

A estas afinidades, terminológicas y conceptuales, podemos agregar otros interesantes paralelismos lingüísticos. Por ejemplo, los términos diseño y dibujo refieren a la misma raíz etimológica, e incluso en algunos idiomas actuales (como el italiano o el inglés) se designan con la misma palabra. Por otra parte, según del diccionario de la RAE, la etimología de proyectar viene del latín proiicěre, que significa "arrojar". Por eso la primera de las definiciones que nos propone el diccionario es: "lanzar, dirigir hacia delante o a distancia". Esto debe interpretarse en el sentido de la capacidad de prefiguración de un futuro posible. A su vez, prefigurar implica "representar anticipadamente algo", o sea, generar figuras. De la misma forma que imaginar (volviendo a la frase de Le Corbusier) es la facultad para generar imágenes en la mente.

Todas las anteriores definiciones, etimologías y sinonimias nos hablan de una íntima relación entre el proyecto y la representación. En definitiva, para las disciplinas ligadas al diseño el dibujo es la principal herramienta del pensamiento proyectual, dado que es una ayuda insustituible para la imaginación y la prefiguración de ese "futuro posible" que es el proyecto.

\section{LAS OBRAS ESTUDIADAS}

Para llevar a cabo el ejercicio de revelamiento métrico y representación gráfica, seleccionamos espacios exteriores de uso público: los patios de la Casa de la Cultura de Maldonado, el jardín en esquina del Cuartel de Dragones de Artigas y un sector del patio del Paseo de San Fernando. Los tres edificios se encuentran próximos entre sí y gravitan en torno a

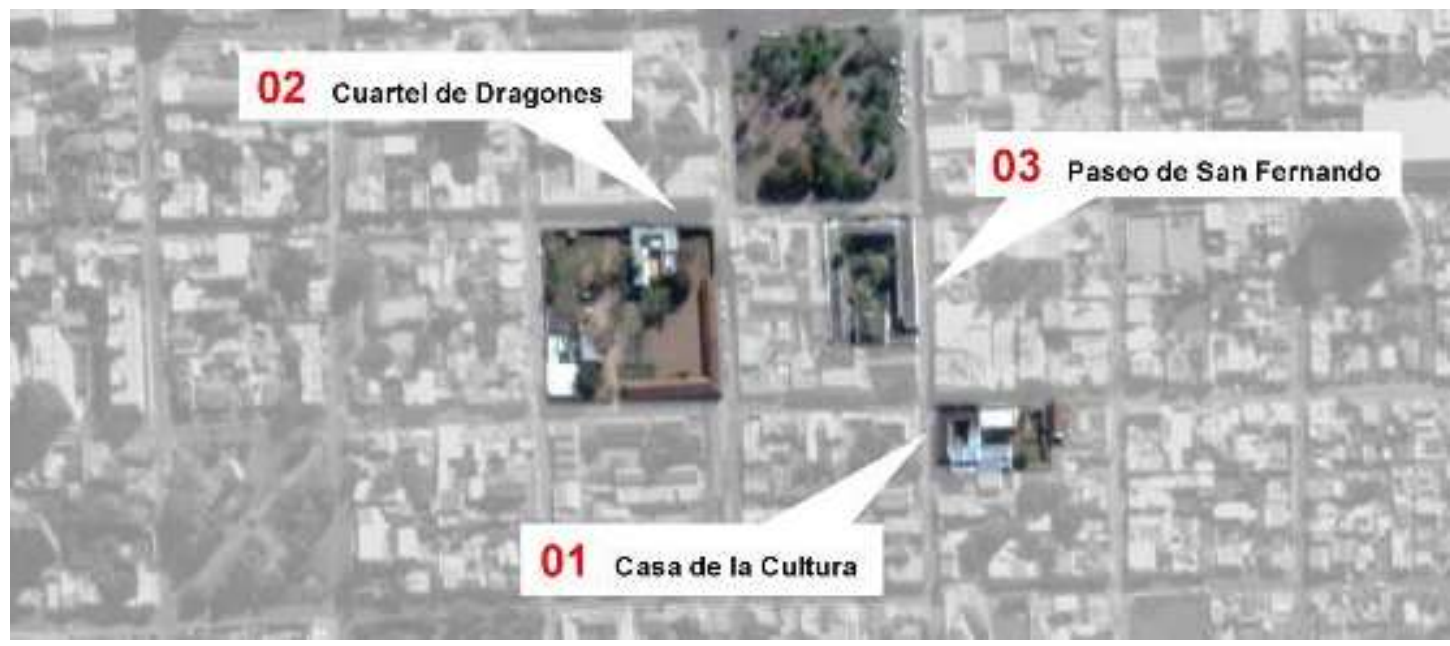

la Plaza de San Fernando, centro físico y simbólico de la ciudad de Maldonado (ver figura 02).

En definitiva, se trata de tres espacios exteriores que, además de su interés arquitectónico y paisajístico, poseen valor histórico y cultural para la población de Maldonado. Por ello nos interesa especialmente promover en los estudiantes el conocimiento de estos espacios dedicados a la cultura local.

Figura 2. Trama urbana de Maldonado y ubicación de los tres espacios con respecto a la Plaza 


\section{de San Fernando.}

Fuente: producción propia a partir de foto área de Google Maps.

\section{Casa de la Cultura de Maldonado}

Ubicado en la esquina de las calles Sarandí y Rafael Pérez del Puerto, se trata de un edificio construido en 1875 que fue sucesivamente utilizado como jefatura de policía, escuela pública, dependencia de aduana y oficinas de la Intendencia Municipal de Maldonado. A partir de 1985 fue adoptado por la Dirección de Cultura y allí se instaló la Escuela Municipal de Artes Plásticas, por lo que en sus instalaciones hoy se realizan exposiciones, charlas y diversas reuniones de

grupos culturales locales (ver:

Casa de la Cultura de Maldonado, s.f.). El edificio incluye dos espacios exteriores de uso público. El primero es un pequeño patio con una fuente en el centro; el segundo, un jardín enmarcado por pérgolas y galerías techadas que se comunican con la calle.
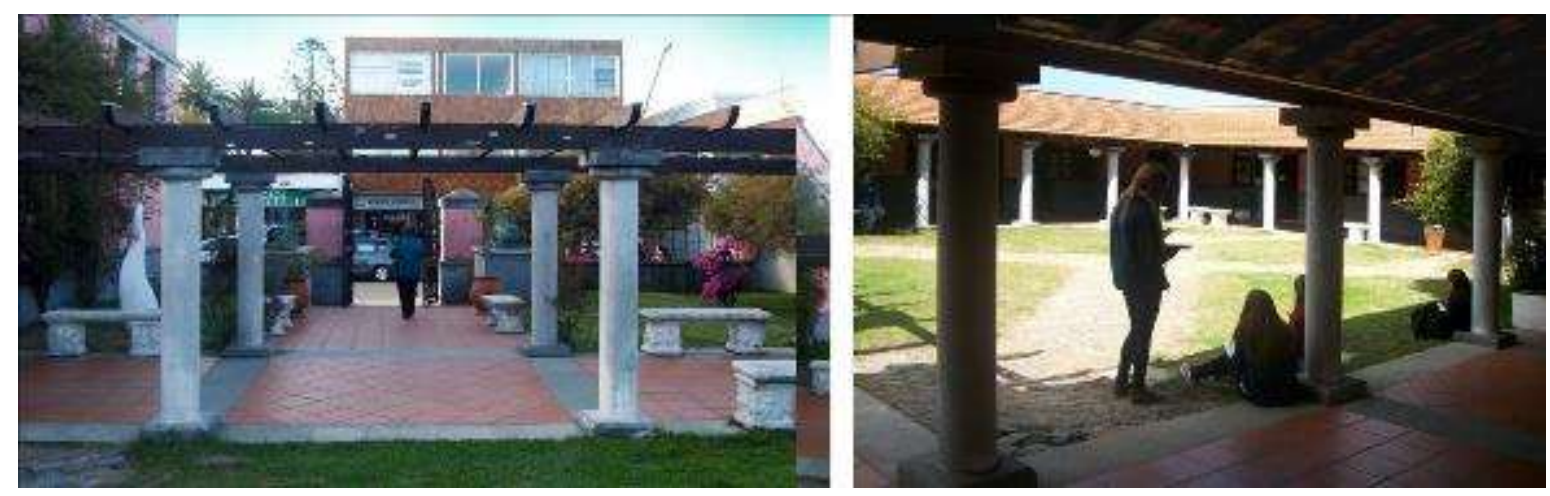

Figura 3. Segundo patio de la Casa de la Cultura de Maldonado. Fuente: fotografías producción propia.
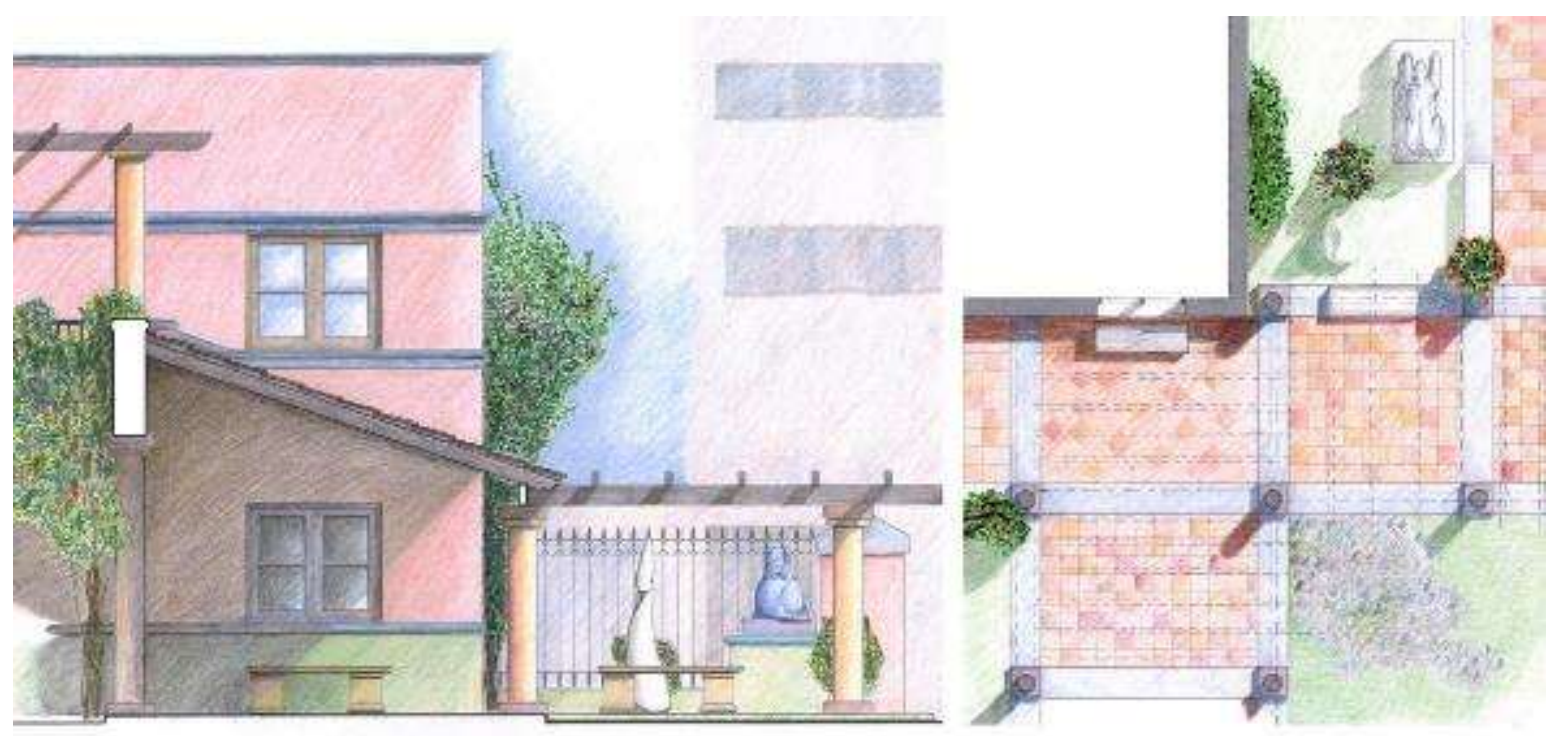
Figura 4. Casa de la Cultura de Maldonado. Sección y Planta expresadas con lápices de colores.Trabajo del estudiante Leonardo Barrios.

\section{Cuartel de Dragones}

El segundo ejemplo es una instalación militar que ocupa una manzana completa de la trama urbana de Maldonado. Su construcción se remonta al año 1771 y está históricamente vinculado al "cuerpo de blandengues" al que perteneció nuestro máximo prócer, el general José Artigas (ver: Tonera, 2007). Actualmente sigue funcionando como dependencia del ejército, pero en algunos de sus locales se realizan exposiciones abiertas al público y actividades civiles. El sector del patio que mira hacia la Plaza de San Fernando (ubicado en la esquina de las calles 18 de julio y 25 de mayo) funciona como espacio público de la ciudad de Maldonado. Este espacio está cerrado a ambas calles por altos muros de piedra que reconstruyen las ruinas del antiguo edificio. A su vez, los muros están perforados por huecos que se protegen con rejas de hierro, de manera que limitan el acceso, pero permiten una relación visual con la calle. En definitiva, aunque este espacio no tiene galerías está tratado como un jardín contenido por elementos arquitectónicos en casi todo su perímetro, lo que lo aproxima a la tipología de patio con galerías.

Figura 5. Cuartel de Dragones. Fotos del estudiante Diego Rodríguez.
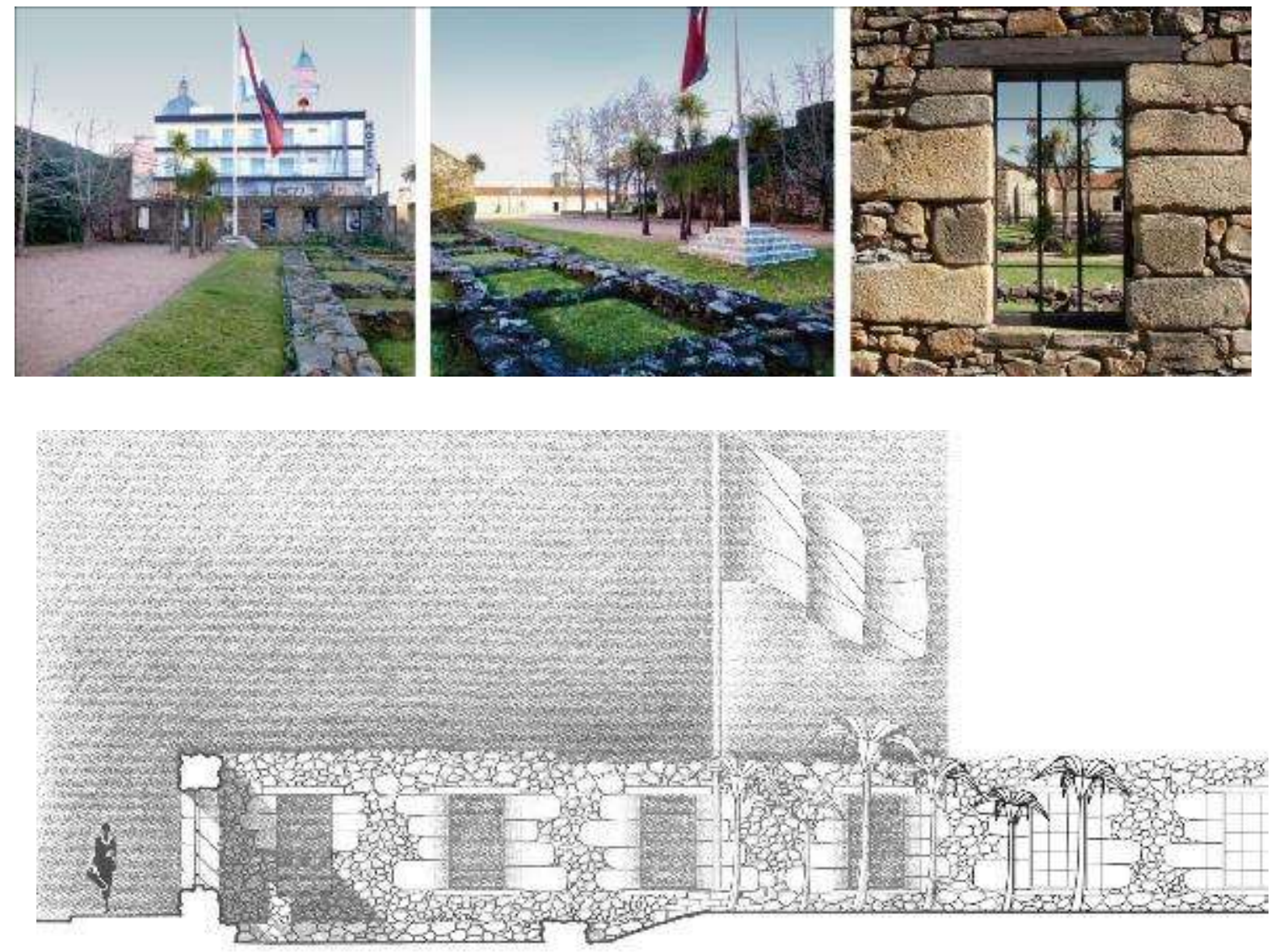

Figura 6. Sección vertical del Cuartel de Dragones. Trabajo en técnicas mixtas.Trabajo del estudiante Diego Rodríguez. 


\section{Paseo de San Fernando}

Más similar al primer caso que al segundo, este edificio posee un generoso patio con abundante vegetación y está rodeado de dos niveles de galerías. Ubicado frente a la plaza

de San Fernando (en la esquina que forman las calles 25 de Mayo y Sarandí) se trata de una obra mucho más reciente, ya que su construcción data de 1909. Destinada originariamente a cuartel militar, el edificio fue restaurado en 1985 como centro cultural y sede del Municipio de la ciudad de Maldonado. En 2015 fue declarado "Sitio de la memoria de Maldonado" ya que durante la dictadura cívico-militar (1972-1985) funcionó como centro clandestino de detención y tortura (ver: Colocan "Marca de la Memoria" en Paseo "San Fernando", 2015). En definitiva, promover el patrimonio no consiste solamente en destacar los valores positivos, sino que a veces esa defensa se relaciona con lo más oscuro de nuestra historia, pues las heridas que aquella nos deja también configuran nuestra memoria y definen nuestro patrimonio actual.
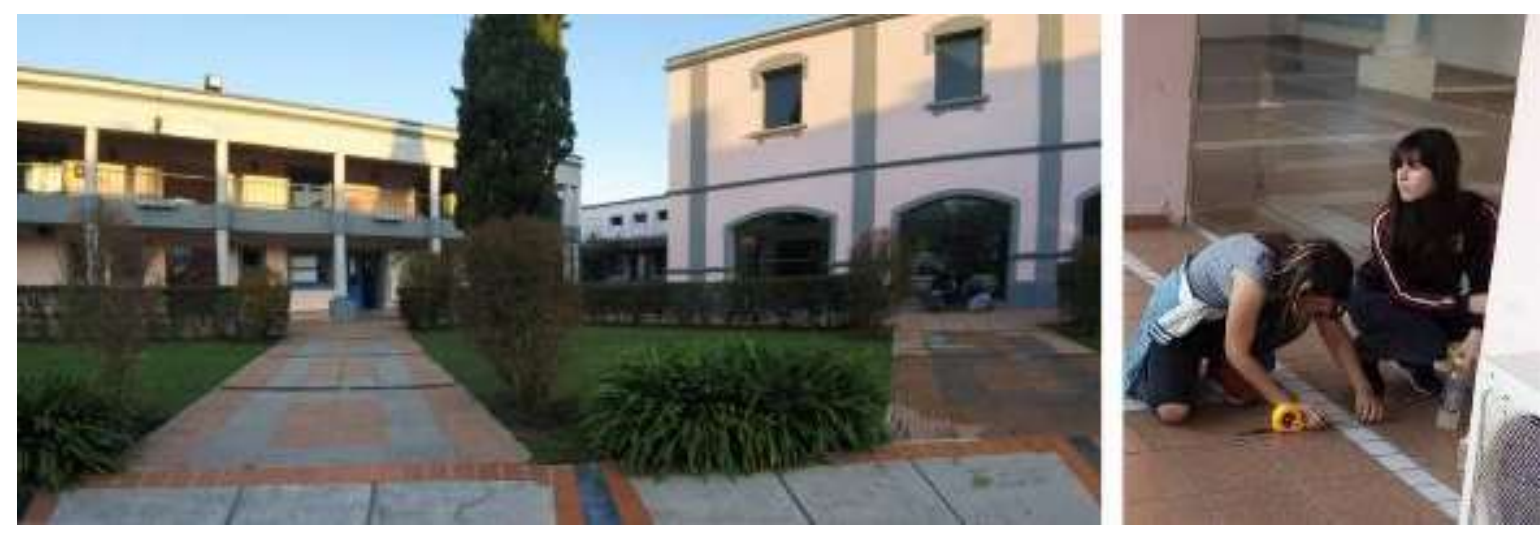

Figura 7. Estudiantes relevando el Paseo de San Fernando. Curso 2017.

En resumen, los tres casos estudiados pueden definirse como: espacios exteriores con características de patio que son parte de edificios públicos con significación cultural local. En todos ellos el edificio actúa como el marco del vegetal, y la vegetación actúa como complemento de lo edilicio. Por lo general, esta fuerte interrelación entre paisaje y arquitectura se produce en menor medida en una plaza urbana y no se suele producir en un parque. Por todos estos motivos los ejemplos estudiados ofrecen un excelente potencial para ensayar la representación de los espacios exteriores y los vegetales que lo pueblan.

\section{METODOLOGÍA}

El curso Representación Gráfica del Espacio II (RGE2) se ubica en el segundo semestre del primer año de la Licenciatura de Diseño de Paisaje (LDP). Según el Plan de Estudios de la LDP la asignatura RGE pertenece al eje temático de las "Prácticas Proyectuales", por ello entre sus objetivos el Plan establece que nuestra asignatura:

Instruye acerca de las principales herramientas de representación del espacio al servicio del diseño y el proceso del proyecto. La práctica se centra en lo relativo a los medios y técnicas de representación y ejercita al estudiante en el registro de los elementos del paisaje y sus aplicaciones (Plan de Estudios, 2011). 
Es decir, desde el propio Plan se define la estrecha relación existente entre la representación y el proyecto. Por ello, los docentes de RGE consideramos que la enseñanza de las herramientas de representación debe estar directamente referida a la enseñanza del proyecto. En esta línea es que se inscribe la propuesta pedagógica desarrollada en el curso.

\section{Objetivos del ejercicio}

La metodología que hemos venido implementando en el curso responde a tres objetivos principales.

En insoslayable primer lugar tenemos el objetivo pedagógico. El trabajo responde directamente a los contenidos específicos y las didácticas de la asignatura RGE: la enseñanza y el aprendizaje de las técnicas y los códigos de representación gráfica en Sistema Diédrico Ortogonal (SDO). En este sentido el relevamiento de un espacio existente se presenta como una herramienta adecuada para ensayar diferentes técnicas de representación de plantas, fachadas y cortes de un espacio exterior.

En segundo lugar, ponemos al objetivo proyectual. Como marcábamos en el apartado anterior, mediante este ejercicio se intenta relacionar la representación con el proyecto y se espera que los estudiantes logren una mayor comprensión del espacio estudiado para realizar el análisis de una realidad existente.

En tercer lugar, el ejercicio pretende lograr un objetivo extra-académico. Al estudiar espacios que tienen un interés cultural, además de su valor paisajístico y arquitectónico, se busca propender a un mayor conocimiento y revalorización del patrimonio local por parte de los estudiantes.

\section{Premisas del ejercicio}

Uno de los motivos pragmáticos que está detrás de la elección de estos espacios públicos es que todos permiten un libre acceso (o al menos tienen mínimas limitaciones de horario) ya que, para hacer un relevamiento, por lo general, los espacios deben visitarse en varias oportunidades. Por otro lado, la proximidad con el CURE permite que el equipo docente también pueda concurrir a los sitios junto con los estudiantes.

\section{Etapas de trabajo}

El ejercicio abarca, prácticamente, todo el segundo semestre académico de la LDP y se divide en varias fases que tienen diferentes objetivos y que terminan cada una con una entrega de láminas gráficas. El objetivo de todo el trabajo es realizar un relevamiento de geometrales en Sistema Diédrico Ortogonal (SDO). Es decir, se dibujan plantas, cortes y fachadas dibujados a escala, aunque también se realizan algunos croquis perspectivos.

\section{Relevamiento in situ}

Esta primera etapa de relevamiento se lleva a cabo in situ y tiene por objetivos hacer un reconocimiento del edificio y obtener datos para luego representarlo. Para ello los estudiantes realizan relevamientos dimensionales, croquis y registros fotográficos. El relevamiento 
dimensional consiste en la toma de medidas de los espacios y elementos estudiados. Para registrar los datos se utiliza básicamente la modalidad de dibujo croquisado (dibujo rápido a mano alzada o a pulso), mientras que el registro fotográfico sirve como apoyo a la toma de dimensiones. Para repartir las tareas de relevamiento los estudiantes forman grupos de 304 integrantes. Estos grupos deben producir una primera versión gráfica del relevamiento.

\section{Dibujo técnico}

A partir de la información dimensional y los croquis obtenidos en la etapa grupal, cada estudiante realiza algunas piezas gráficas en forma individual. El equipo docente define una serie básica de proyecciones geometrales (plantas y cortes) que los estudiantes deben realizar (ver figura 08). Primero los dibujos se realizan con instrumental técnico (trazados en lápiz grafito) y luego mediante dibujo digital (software de dibujo asistido, CAD). Al realizar estos dibujos los estudiantes aprenden el manejo de diferentes recursos gráficos (valoración lineal, expresión de texturas, dibujo de vegetales, etc.) a la vez que se les enseña a aplicar la codificación gráfica que es específica del dibujo técnico de geometrales.
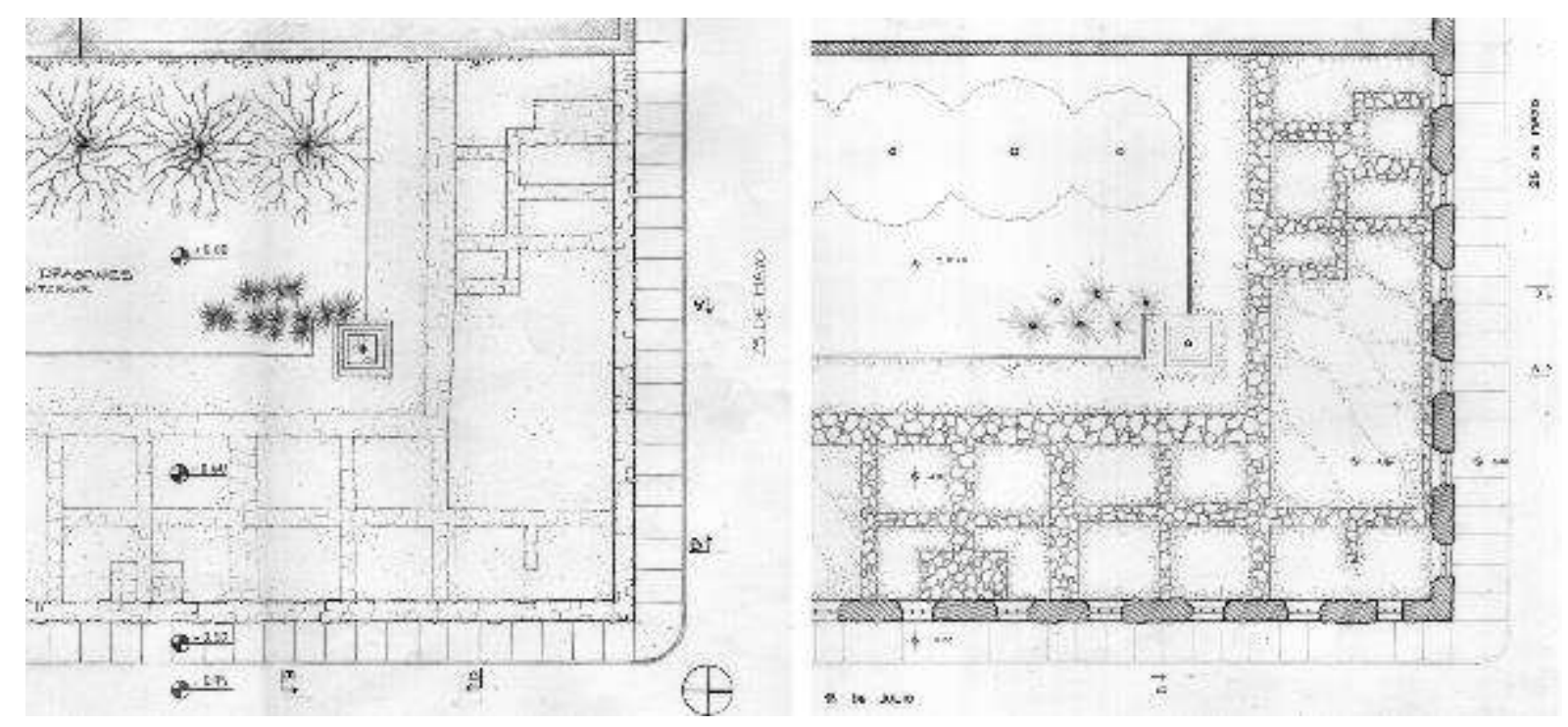

Figura 8. Plantas del Cuartel de Dragones. Trabajo de los estudiantes Emiliana Calavia y Diego Rodríguez.

\section{Trazado de sombras y expresión en grises}

Tomando como base los dibujos producidos en la etapa anterior, los estudiantes deben hacer el cambio de escala de un sector del espacio. En estos nuevos dibujos incorporan el trazado de sombras y ensayan la expresión en claroscuro mediante lápiz grafito. Los gráficos ganan interés y expresividad al incluir detalles de la materialidad de la arquitectura y texturas figurativas en los vegetales (ver figura 06).

\section{Expresión a color}

En esta etapa se ensaya la expresión a color a partir de las mismas piezas realizadas en la etapa anterior (ver figuras 09 y 10). Se alienta a los estudiantes a que incorporen técnicas mixtas, por ejemplo: tomando como base piezas de dibujo lineal (realizadas mediante CAD) 
para luego expresarlas a color mediante técnicas tradicionales (acuarelas, lápices de colores, etc.).
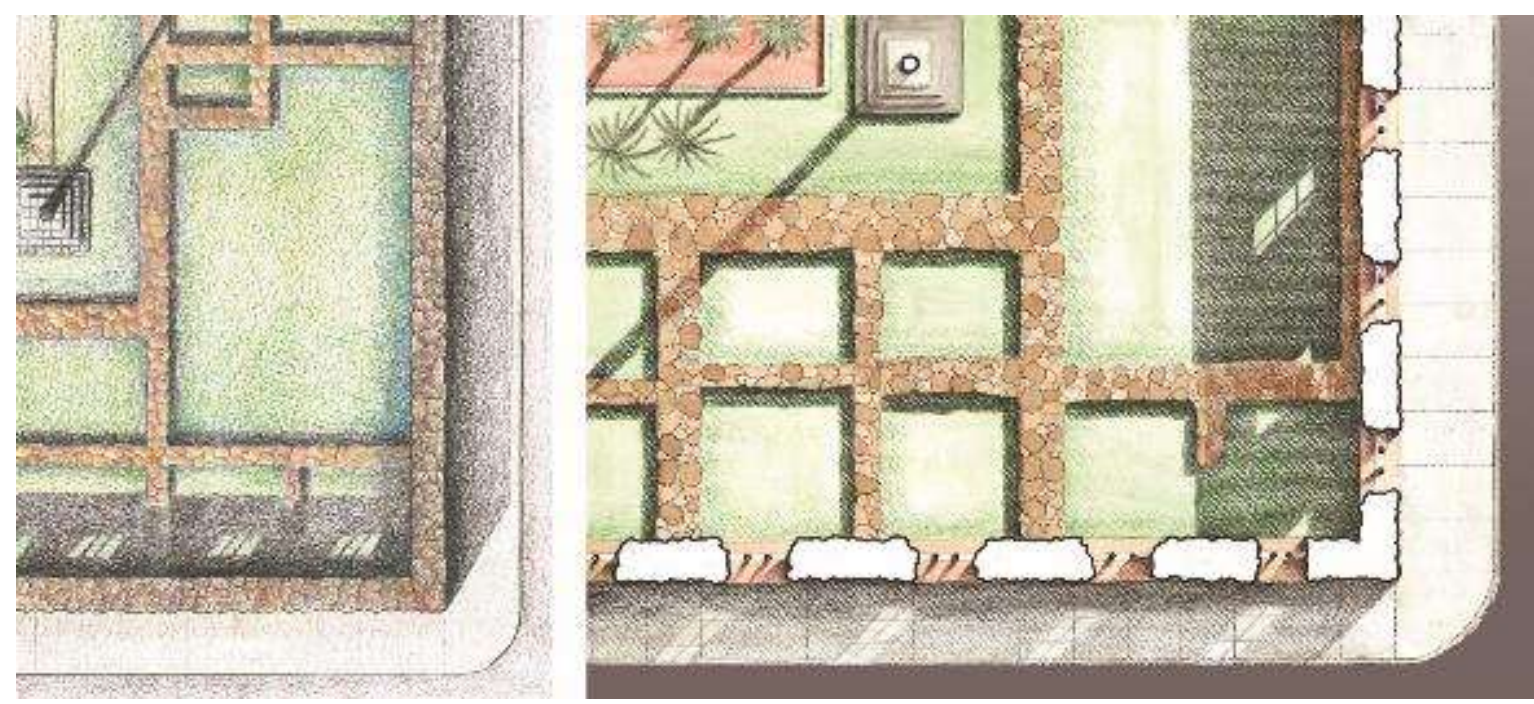

Figura 9. Cuartel de Dragones. Plantas con expresión a color (acuarela y lápices de colores).Trabajos de los estudiantes: Emiliana Calavia y Diego Rodríguez.

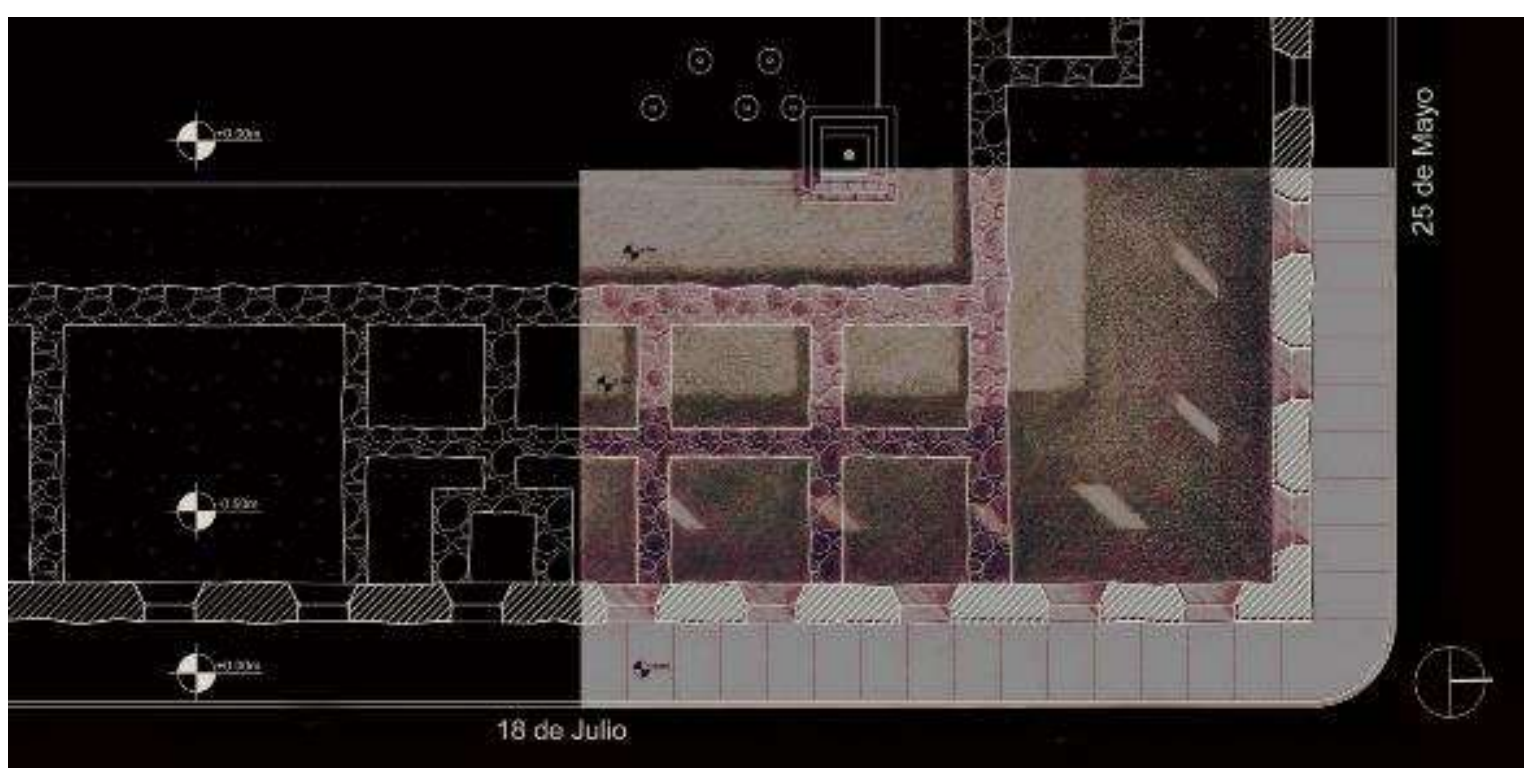

Figura 10. Planta del Cuartel de Dragones. Expresión en técnicas mixtas.Trabajo de la estudiante Paula Beltrán.

\section{Presentación final}

Finalmente, los gráficos producidos en diferentes técnicas y estilos gráficos se integran en una única lámina, diseñada para comunicar el espacio relevado. Esta lámina funciona como entrega final del curso. Para llevar a cabo este trabajo los docentes enseñamos algunas técnicas de 
composición de formato e incorporamos el uso de otras herramientas gráficas digitales (CorelDraw o un software digital similar).

\section{CONCLUSIONES Y DISCUSIÓN}

A modo de resumen, podemos concluir que este trabajo presenta para nosotros múltiples aspectos positivos que conviene exponer.

En primer lugar, el ejercicio resulta lo suficientemente estimulante para incitar el aprendizaje de los estudiantes y lo suficientemente efectivo para aplicar diferentes recursos de enseñanza por parte de los docentes. Esto es así porque el relevamiento de un espacio existente nos obliga (en el buen sentido de la palabra) a observar con atención, a analizar y a tratar de entender el espacio que se representa.

En segundo lugar, esta actividad implica establecer una relación y generar un compromiso social con la comunidad en donde se dicta la Licenciatura. Consideramos que resulta positivo el involucramiento de los estudiantes en ese sentido. En tanto que la representación de un espacio existente, además de permitir el aprendizaje de las herramientas gráficas, se constituye en una manera de re-significar el valor cultural de los ejemplos estudiados. En definitiva, se trata de un patrimonio cultural que es propio, pero que muchas veces es escasamente valorado o permanece totalmente desconocido. Lo que aproxima a esta actividad a una experiencia de extensión universitaria.

En tercer lugar, es un hecho comprobado que la mayoría de los estudiantes que cursan Ia LDP residen en el departamento de Maldonado El estudiar espacios culturales vinculados al medio local genera, en los estudiantes, mayor pertenencia con el objeto de estudio y propende a un mayor conocimiento del lugar en donde la licenciatura se dicta.

En cuarto lugar, el ofrecer herramientas gráficas para estudiar los espacios se vincula a la enseñanza con la práctica proyectual que se desarrolla en los talleres de proyecto. Hay que considerar que durante el segundo semestre nuestro curso se dicta simultáneamente con la asignatura de taller de proyecto, por lo tanto, en paralelo a esta ejercitación los estudiantes están desarrollando ejercicios proyectuales en los que podrían aplicar los conocimientos aprendidos en nuestra asignatura.

A lo largo de los años que hemos venido realizando este ejercicio, las principales dificultades detectadas por el equipo docente radican en la fidelidad con la realidad estudiada, planteada como una característica definitoria. Esto conlleva un trabajo exhaustivo de toma de datos y sucesivos ajustes de las representaciones por parte de los estudiantes. Es claro que el hecho de estudiar un referente real constituye un verdadero desafío para los estudiantes.

Por último, es un objetivo, aún pendiente, del equipo docente el poder dar una adecuada difusión pública al trabajo realizado. En ese sentido en diciembre de 2014 se realizó en la Facultad de Arquitectura de Montevideo una exposición de algunos de los trabajos producidos por los estudiantes de RGE2 durante el relevamiento del Cuartel de Dragones. En este momento el trabajo en el Paseo de San Fernando está en plena evolución. Una vez finalizado estamos estudiando la posibilidad de exponer algunos trabajos en el Paseo de San Fernando. 


\section{BIBLIOGRAFÍA}

Besse, J. (2008). Las cinco puertas del paisaje. En: Paisaje y pensamiento (145-172). Madrid: Abada.

Casa de la Cultura de Maldonado. (2017). Recuperado de: http:/ / bit.ly/ 2wynNwj

Casa de la Cultura de Maldonado. (s:f.). Recuperado de: http:// bit.ly/ 2zZaaYK

Colocan "Marca de la Memoria" en Paseo "San Fernando" (2015). Recuperado de: http:// bit.ly/2ydLPS3

Colomina, B. (2010). Privacidad y publicidad: La arquitectura moderna como medio de comunicación de masas. Murcia: Coamu-Cendeac.

De Lapuerta, J. M. (1997). El croquis, proyecto y arquitectura. Madrid: Celeste ediciones.

Folga, A., Espinosa, C. (2016) La representación gráfica del proyecto de Paisaje. Investigación inédita.

Folga, A., Gómez, L. (2016). La Trazabilidad del patrimonio arquitectónico del Estado. XX Congreso de la Sociedad Iberoamericana de Gráfica Digital, 595-600.

Folga, A. (2017). Imágenes Alteradas: un ejercicio de interpretación gráfica sobre el sitio de proyecto. Ponencia presentada al congreso SIGRADI XXI.

Hutchinson, E. (2012). El dibujo en el proyecto del paisaje. Barcelona: Gustavo Gili.

Plan de Estudios, LDP (2011). Recuperado de: http:// www.fadu.edu.uy/ldp/informaciongeneral/ plan-estudios/

Tonera, R. (2007). Cuartel de Dragones de Maldonado. Recuperado de: http:/ / bit.ly/ 2ieGCOQ

Velázquez, R., Perdomo, A. (1992). La Enseñanza en los Talleres de Anteproyecto, Método didáctico y evaluación de resultados en una enseñanza masificada.

Waterman, T., Wall, E. (2013, agosto). Un diálogo con el paisaje: proyecto, representación y proceso. Urban, 5, 37-48. 